\title{
SUSTENTABILIDADE SOCIAL, SOCIEDADE DA TRANSPARÊNCIA E O DIREITO DE SER HUMANO
}

\author{
SOCIAL SUSTAINABILITY, SOCIETY OF TRANSPARENCY
} AND THE RIGHT TO BE HUMAN

RESUMO: Esta pesquisa tem como objeto de estudo a Sustentabilidade na sua dimensão social. Nesse caso, é preciso identificar se as premissas de uma Sustentabilidade social permitem a efetividade de um "Direito de ser humano" a partir daquilo que se manifesta pelas relações entre as pessoas numa Sociedade da Transparência. O objetivo geral é determinar como a Sustentabilidade social efetiva o "Direito de ser humano" na Sociedade da Transparência. O método utilizado na fase de investigação foi o Indutivo. Nas conclusões, verifica-se que Sociedade da Transparência prescreve alguns modos de integração prejudiciais às relações intersubjetivas e que devem sofrer necessárias metamorfoses para que haja a amplitude e reivindicação deste "Direito de ser humano".

Palavras-chave: Direito de ser humano. Sociedade da Transparência. Sustentabilidade. Sustentabilidade social.
ABSTRACT: This paper has as its object the Social Sustainability. It's necessary to identify if the premises of a Social Sustainability allow the effectiveness of a "Right to be human" from what is expressed by the relationships in a Transparency Society. The objective is to determine how Social Sustainability effectively "the right to be human" in the Transparency Society. The method used in the investigation was Inductive. At the conclusions, the Society of Transparency prescribes harmful relations that needs to undergo by deep metamorphoses in order to claim this "Right to be human".

Keywords: Right to be human. Sustainability. Social Sustainability. Tranparency Society.

\footnotetext{
${ }^{1}$ Doutor e Mestre em Ciência Jurídica pela Universidade do Vale do Itajaí. Professor Permanente e Pesquisador do Programa de Mestrado em Direito da Faculdade Meridional - IMED. Coordenador do Grupo de Pesquisa "Ética, Cidadania e Sustentabilidade".
} 


\section{INTRODUÇÃO}

O século XXI põe em evidência as limitações das ideologias, das aspirações históricas, dos projetos civilizacionais desenvolvidos pela Modernidade. A dinâmica das relações de tornam mais amplas, mais virtuais. A velocidade dessas conexões humanas não é acompanhada, tampouco compreendida pelas tradições do Direito Positivo. Pode-se afirmar que as exigências sociais do tempo presente não estão em sintonia com a racionalidade e discurso jurídico. Quando as sociedades se tornam cada vez mais complexas, torna-se dificultoso, num cenário de necessidades difusas, que a homogeneidade da prescrição normativa alcance as especificidades de cada relação humana.

A Sustentabilidade ${ }^{2}$ é uma dessas exigências, cujos objetivos e programas não se exaurem mediante uma jurisdição e legislação nacional, mas se aperfeiçoam pela compreensão de sua matriz ecológica e interdisciplinaridade nos diferentes níveis de significação e articulação política, jurídica, ambiental, econômica, histórica, cultural, territorial, entre outros. Trata-se de um esforço em produzir mudanças comportamentais e cognitivas com impacto significativo na relação do Homem com a Natureza. A proteção da vida e dignidade não podem mais ser defendidas numa postura antropocêntrica, visando apenas a sobrevivência da família humana, mas de outra percepção: a Dignitas Terrae.

Nesse caso, a Sustentabilidade, quando entendida pela sua dimensão social, busca concretizar um "meio-termo" relacional capaz de assegurar formas de convivência pacifica e sadias entre os seres humanos, bem como empreende atitudes no sentido da mitigação, da superação das desigualdades e misérias no mundo. Ao se ter a clareza da Sustentabilidade social como vetor de orientação às relações intersubjetivas, não se pode(ria) admitir o surgimento de sociedades que eliminassem, simplificassem ou reduzissem a execução desses objetivos locais e globais.

\footnotetext{
${ }^{2}$ Quando a palavra aparecer sem qualitativos, essa deve ser compreendida pelo seguinte conceito operacional: Compreensão ecosófica acerca da capacidade de resiliência entre os seres e o ambiente para se determinar - de modo sincrônico e/ou diacrônico - quais são as atitudes que favorecem a sobrevivência, a prosperidade, a adaptação e a manutenção da vida equilibrada.
} 
No entanto, o caso da Sociedade da Transparência merece atenção de ser estudada na medida em que as regras sociais ali prescritas demonstram pouca convergência às reinvindicações históricas da Sustentabilidade social para se desenhar o projeto de uma sociedade mundial ${ }^{3}$. O "Direito de ser humano" deve ser a expressão das conquistas sincrônicas e diacrônicas - da Sustentabilidade social no decorrer do tempo.

A partir dessa linha de pensamento, o problema de pesquisa formulado para este estudo pode ser descrito pela seguinte indagação: Como a Sociedade da Transparência desenvolve as regras para a composição da paz e do "Direito de ser humano" a partir dos critérios enunciados pela Sustentabilidade social?

A hipótese para essa pergunta sinaliza, provisoriamente, uma postura de desumanização das relações frente às características da Sociedade da Transparência. O esgotamento da saúde mental, a excessiva "positividade" em se tentar superar os problemas cotidianos, a eliminação de certas fases da vivencia e convivência como pressupostos ao aperfeiçoamento de nossa humanidade comum são elementos que pouco convergem à manutenção da Sustentabilidade social e à exigibilidade do "Direito de ser humano".

O objetivo geral deste estudo é determinar como a Sustentabilidade social efetiva o "Direito de ser humano" na Sociedade da Transparência. Os objetivos específicos são: a) Esclarecer a importância dos fundamentos epistemológicos da Sustentabilidade; b) Definir o que é a Sustentabilidade social; c) identificar as principais características da Sociedade da Transparência e sua relação com efetividade do "Direito de ser humano".

A partir desses argumentos, o critério metodológico utilizado para a investigação e a base lógica do relato dos resultados apresentados reside no método indutivo ${ }^{4}$, cuja premissa maior é o reconhecimento da Sustentabilidade na sua dimensão social como vetor de desenvolvimento civilizacional e a premissa menor é a efetividade do Direito de

\footnotetext{
3 "As sociedades contemporâneas, a despeito de suas diversidades e tensões internas e externas, estão articuladas numa sociedade global. Uma sociedade global no sentido de que compreende relações, processos e estruturas sociais, econômicas, políticas e culturais, ainda que operando de modo desigual e contraditório" (IANNI, 2008, p. 39).

${ }^{4}$ Para Pasold, trata-se da "[...] base lógica da dinâmica da Pesquisa Científica que consiste em pesquisar e identificar as partes de um fenômeno e colecioná-las de modo a ter uma percepção ou conclusão geral” (PASOLD, 2018, p. 215).
} 
ser humano na Sociedade da Transparência. As técnicas utilizadas nesse estudo serão a Pesquisa Bibliográfica ${ }^{5}$, a Categoria ${ }^{6}$ e o Conceito Operacional ${ }^{7}$.

\section{A IMPORTANCIA DA SUSTENTABILIDADE NA SUA DIMENSÃO SOCIAL}

Pensar e viver a Sustentabilidade como reivindicação histórica e axiológica do século XXI é um desafio ambíguo, ou seja, sabe-se da sua importância para que hajam outras compreensões da relação entre os seres humanos e desses com o mundo natural, mas a sua efetividade se torna precária devido ao seu projeto universalista e às ideologias que reinventam velhas ideias como soluções para a alvorada desse "admirável mundo novo".

Sustentabilidade, quando entendida fora de sua matriz ecológica, é uma daquelas palavras que pode ser tudo e nada ao mesmo tempo. Ao se determinar a passagem do "substantivo" ao "adjetivo", qualquer produto, qualquer ideia, qualquer prática se torna uma virtude civilizacional. Entretanto, ao se mergulhar no fundo dessas aparências, percebe-se como o seu conteúdo destoa dos objetivos pretendidos. A tarefa de se identificar o que é a Sustentabilidade denota uma experiência sensível e uma racionalidade que não podem ser confundidas com outros ramos do conhecimento. Sustentabilidade é fenômeno com identidade e identificações próprias, capaz de transitar entre os saberes e sintetizar novas utopias que alteram a transição de uma realidade insuportável para outra desejável.

Sustentabilidade, nesse caso, denota uma ecosofia, uma avaliação entre múltiplos campos do viver e conhecer que se manifestam pela interação entre seres e ambientes. A partir desse pressuposto, é possível saber o grau de resiliência dessas aproximações, dessas interferências - sejam sincrônicas e/ou diacrônicas - para que haja nossa adaptação, prosperidade e sobrevivência no transcorrer dos tempos.

\footnotetext{
${ }^{5}$ Segundo o mencionado autor: "[...] Técnica de investigação em livros, repertórios jurisprudenciais e coletâneas legais." (PASOLD, 2018, p. 217).

${ }^{6}$ Nas palavras de Pasold: “[...] palavra ou expressão estratégica à elaboração e/ou expressão de uma ideia” (PASOLD, 2018, p. 207).

${ }^{7}$ Reitera-se conforme Pasold: “[...] definição estabelecida ou proposta para uma palavra ou expressão, com o propósito de que tal definição seja aceita para os efeitos das ideias expostas" (PASOLD, 2018, p. 207). Toda Categoria que aparece neste estudo será destacada com letra maiúscula.
} 
A Humanidade está na corda bamba de sua autoanálise, de sua autocompreensão, de reconhecimento nas diferenças alheias, sejam humanas e não humanas. Há pouca, para dizer quase nenhuma, Sustentabilidade social capaz de prover articulação entre os povos e gerar condições de luta contra as desigualdades, contra a miséria humana, contra a efetividade de uma Ecologia Integral, de uma forma de ação centrada numa Cidadania continental ou global ${ }^{8}$, cujos fundamentos são ao Direitos Humanos e o Direito Global ${ }^{9}$.

Os próprios seres humanos, insiste-se, desfazem todo o tecido da socialidade. As suas bases, agora, constituem-se de outros valores os quais criam a segregação, a eliminação, o ódio, o ressentimento. Tudo é travestido sob o manto de Democracia e, ainda, sob o nome "Liberdade de Expressão". Pouco a pouco, tudo se corrói, se dissolve e nada restará daquilo que favorece a integração das relações humanas cotidianas. Esse é um cenário distópico para o século XXI.

Apesar dessas situações serem óbvias para muitas pessoas, o grau de clareza aqui exigido, talvez, não seja compatível com os pressupostos da Sustentabilidade social. Somente podemos acreditar que um fenômeno é obvio a partir do momento de que se consegue os esclarecimentos necessários sobre os seus significados no momento presente. Não existe qualquer perspectiva de utopias para a realização do futuro sem a habitualidade de ações que se perpetuam pelo viver, pela práxis do cotidiano no tempo presente. Por esse motivo, nenhuma obviedade é clara sem que haja seu permanente desvelo no "aqui e agora".

Nessa linha de pensamento - e como pressuposto para se tirar o véu da obviedade de uma sociedade nada sustentável, mas travestida pela normalidade da indiferença e assegurada constitucionalmente pela "Liberdade de Expressão" - torna-se necessário desenhar os contornos da Sustentabilidade social, da sua compatibilidade com a realidade

\footnotetext{
8 “A Cidadania não pode mais ser caracterizada como unilateral, particular e descompromissada com outras localidades da Terra. Num mundo interdependente, a manifestação cidadã que se limita às fronteiras nacionais colabora para aumentar as misérias, as guerras, a individualidade solipsista, a indiferença endêmica e a insustentabilidade planetária" (AQUINO, 2014, p. 421).

9 “Há que se pensar, nas fileiras do Direito Global, no amadurecimento de uma carta contendo itens de um patrimônio comum da humanidade, tais como: proteção ambiental; direito ao desenvolvimento humano; alimentação adequada; direito ao conhecimento; direito à ajuda e consolidação dos primados de autonomia humana, afinal, sem ela, não há dignidade da pessoa humana" (STAFFEN, 2018, p. 163).
} 
histórica, bem como dos domínios que compõem a sua autocompreensão no tempo, nos espaços e diálogos entre as pessoas.

Para se compreender melhor o objetivo deste estudo, comecemos pelo último ponto: os domínios de existência ou de indícios de uma Sustentabilidade social, ou, ainda, do seu contrário, de uma Insustentabilidade social. É interessante anotar que o foco de atenção, o núcleo forte dessa dimensão da Sustentabilidade - categoria entendida, aqui, sob a sua matriz ecológica - precisa compreender o ser humano nas suas peculiaridades, ou seja, naquelas características que o descrevem como existência dotada de autonomia, autoanálise e consciência de si, de seus pensamentos e atitudes. Não somos anjos, não somos bestas, somos o fruto da vida que se desenvolveu, se aperfeiçoou e, ainda, nas suas contingências, tece cada fio de identidade e identificação do Homo Sapiens Sapiens com o mundo no qual dialoga de modo permanente.

O desenvolvimento do Humano, enquanto espécie, não pode ser datado somente a partir de sua capacidade perceptiva a fim de se distinguir dos outros animais. 0 surgimento do Homo Sapiens não é um fenômeno linear e instantâneo, porém, é lento e complexo. Nesse caso - e na medida em que surgem novas mudanças sociais, novas crises de significado dessas interações, bem como se manifestam, como resultado, as metamorfoses humanas - pergunta-se: o humano é apenas a expressão ideológica de seu ultimo estágio evolutivo sintetizado pelo humanismo? A resposta parece negativa.

Observa-se que a composição desse momento da evolução humano sofreu múltiplas interferências, tais como as mudanças no cenário climático, as radicais transformações das florestas para as savanas, e, ainda, sob o ângulo biológico, a liberação das mãos pela postura ereta especialmente com o dedo polegar possibilitou a realização de trabalhos manuais, embora primitivos, citando-se, por exemplo, as ações defensivas e de ataque desses seres contra quem perturbasse o modo de vida daquele Sujeito ou grupo. Nessa perspectiva, o predador é, ao mesmo tempo, a caça.

O cenário descrito demonstra uma transformação que aconteceu (e acontece) de modo complexo entre Hominídeo e Ecossistema. O Homo Sapiens Sapiens não obstante tenha conquistado outros graus de civilidade, cultura, trabalho e tecnologia continua a se desenvolver, biologicamente, sob esses fundamentos, seja nas funções e sistemas de seu 
organismo, seja nas conquistas e avanços de seu trabalho e racionalidade. O Homo Sapiens Sapiens ignora que é, ao mesmo tempo, Homo Ludens, Homo Demens, Homo Faber, Homo Economicus, Homo Aestheticus, entre outros.

Quando não se avalia a vida sob o ângulo da complexidade, de sua capacidade de se auto organizar ou de se autoproduzir ${ }^{10}$, a hominização e suas etapas de desenvolvimento são desprezadas. Novamente, o primado da razão lógica insiste em compartimentalizar ${ }^{11}$ a compreensão sobre os significados manifestos e latentes no desvelo da condição humana. Ignora-se a organização e a integração no diálogo entre os conhecimentos, bem como os limites da consciência ${ }^{12}$ e da percepção ${ }^{13}$.

Os fundamentos de uma Sustentabilidade social, nesse caso, não ignoram a barbárie, a "parte do diabo" que existe em nós, as suas características biopsíquicas, especialmente naquilo que constitui a "consciência coletiva"14", mas os têm como seu ponto de partida para entender as "obviedades" sociais de nosso tempo.

A partir de um exercício de categoria e conceito operacional, pode-se determinar que Sustentabilidade social é a adequação homeostática que se manifesta pela interação entre as diferentes microestruturas sociais e ratificam ou modificam a função coercitiva das macroestruturas sociais no decorrer do tempo e dos espaços.

Parece que fica mais claro, agora, saber o que é a Sustentabilidade social, porém, quais são essas microestruturas sociais? Quais são as macroestruturas? Como ocorre a sua

\footnotetext{
10 “O cérebro não é aqui considerado como um órgão, mas sim como epicentro daquilo que é para nós o essencial da hominização: um processo de complexificação multidimensional, em função de um princípio de auto-organização ou de autoprodução" (MORIN, 2000, p. 56).

11 “Obrigam-nos a reduzir o complexo ao simples, isto é, a separar o que está ligado; a decompor, e não a recompor; e a eliminar tudo que causa desordens ou contradições em nosso entendimento. Em tais condições, as mentes jovens perdem suas aptidões naturais para contextualizar os saberes e integrá-los em seus conjuntos" (MORIN, 2004, p. 15).

${ }^{12}$ A mencionada categoria aparece, segundo o pensamento de Husserl, como vivências intencionais. A Consciência se manifesta pela intencionalidade. Para o filósofo: "A propriedade fundamental dos modos de consciência, que o eu vive como eu, é chamada intencionalidade, é sempre ter consciência de alguma coisa. A este quid da consciência pertencem os modos de ser como existentes, ser presumido, não ser, mas também os modos do ser-aparência, serbom ou ser-de-valor, etc." (HUSSERL, 1992, p. 21). Grifo original da obra em estudo.

${ }^{13}$ No pensamento de Husserl, a "[...] percepção é sensível quando apreende um objeto real, e categorial quando apreende um objeto ideal. [...], na percepção sensível é apreendido diretamente, ou está presente in persona, um objeto que se constitui de modo simples no ato da percepção. Na categorial, em contrapartida, constituem-se novas objetividades" (MORA, 2001, p. 561).

14 "Conjunto das crenças e dos sentimentos comuns à média dos membros de uma sociedade que forma um sistema determinado com vida própria" (DURKHEIM, 1999, p. 342).
} 
atualização e efetivação? Nessa linha de pensamento, precisa-se, também, identificar os domínios da Sustentabilidade social. Essa tarefa não é tão minuciosa quanto às indagações acima realizadas e podem ser feitas com maior tranquilidade. Tem-se, portanto, os seguintes domínios de uma Sustentabilidade social: a) o cotidiano das relações humanas; b) o desenvolvimento da socialidade; c) a formação de redes dos movimentos sociais; d) a amplitude das diferentes formas de globalização; e) a alteração e as novas exigências de participação demandas por outro conceito de Cidadania; f) os mecanismos e espaços de constituição de uma sociedade global; g) a pluralidade da comunicação; h) a solidariedade manifesta pelas atitudes de voluntariado; i) os tipos de sociedade que traduzem as suas máscaras temporais e espaciais - sociedade do cansaço, do desprezo, da decepção, das aparências, da indiferença, de risco, entre outros.

Quando se conjuga o conceito operacional da Sustentabilidade social com os seus domínios, percebe-se momentos de compatibilidade histórica entre as microestruturas sociais e as macroestruturas sociais. O diálogo de complementaridade que existe na sua autoanalise/autocompreensão favorece a existência de mecanismos os quais assegurem a funcionalidade de uma coercibilidade por meio da sua atualização/efetividade.

Muito embora todas essas expressões destacadas sejam um pouco confusas nessa primeira leitura, é possível entende-las a partir das diferentes estruturas que compõem a arquitetura da vida cotidiana. Cada estrutura desempenham funções similares a tantos organismos que existem nos corpos vivos a fim de permitir, de modo harmonioso, o equilíbrio e desempenho dos órgãos vitais. Essa sincronia pode ser entendida como necessária ao desenvolvimento temporal e espacial das relações entre os seres humanos no mundo.

A partir de todos esses argumentos, a Sustentabilidade não pode ser entendida por uma rasa compreensão de efeito e consequência de funções e estruturas sociais, mas, também, dos níveis de sua socialidade, das conexões que são realizadas, da constituição de uma sensibilidade e consciência coletiva, ou seja, de tudo aquilo que não tem importância significativa para se compor uma teoria social da Sustentabilidade.

A obviedade é, ainda, uma esfinge e, aos poucos, está devorando o equilíbrio do corpo social. A necessidade de clareza sobre a sua existência é tema de alta relevância para 
se compreender, minimamente, o porquê a Sustentabilidade é o paradigma social de vida do século XXI.

\section{SUSTENTABILIDADE SOCIAL E SOCIEDADE DA TRANSPARENCIA}

Ao se compreender como a Sustentabilidade como vetor de humanização, de tornar claro esse vínculo comum que habita todas as regiões do mundo para se exigir o "Direito de ser humano". Essa perpétua utopia civilizatória se manifesta quando as relações humanas e sociais modificam a sua forma de ser e de se pensar. Essa atitude precisa ser cultivada, de modo permanente, pelo Profissional do Direito, se quiser entender o mundo que vive e elaborar, interpretar e aplicar as leis de seu próprio tempo.

Nesse caso, o nosso ponto de partida para essa reflexão são duas situações que expressam essa conquista pelo "Direito de ser humano". A primeira refere-se à Sustentabilidade social. A segunda é como identificar - ou não - a presença de relações que entendam os limites e alcance de ser humano na sua socialidade ${ }^{15}$.

A Sustentabilidade exige, para se tornar efetiva no tempo, uma profunda, senão radical mudança no comportamento humano e na sua concepção relacional daqueles que pertencem à família antropos de todos os outros seres vivos nos quais habitam a Terra. Esse acontecimento seria a verdadeira revolução copernicana de nosso tempo. O ser humano, cansado da degradação ao seu redor, empreende atitudes que tornem mais simbiótica a sua condição relacional com a biosfera. Aqui, está um significativo engano: não existem forças capazes de provocar essa sensibilidade no humano enquanto a destruição e a exploração continuarem a serem fontes de lucro.

Será que, a partir dessa lógica, a Sustentabilidade precisa de critérios de maior transparência, de luminosidade quanto ao seu significados e objetivos para trazer um horizonte de viabilidade ao desenvolvimento da vida? Aliás, esse não é o marco principal, a grande reivindicação dos países democráticos com relação à corrupção, à proteção da liberdade e igualdade? Afinal, o que se pretende com a aplicação da transparência em todas as formas de expressão coletiva - seja a social, seja a institucional?

\footnotetext{
15 “[...] A socialidade é a capacidade de convivência, mas também de participar da construção de uma sociedade justa, na qual os cidadãos possam desenvolver as suas qualidades e adquirir virtudes" (CORTINA, 2005, p. 37).
} 
A transparência é a panaceia dos povos democráticos contra a natureza sistêmica da corrupção. É a principal defesa contra a dimensão transnacional de sociedades verdadeiramente plutocratas. A sua função instrumental é de demonstrar, de publicizar o que se faz com o capital gerado pelo trabalho, pela indústria, pelo comércio para se desenvolver a maior parte das atividades de um Estado nacional ou, ainda, desse com outros países no sentido de se fomentar uma racionalidade cooperativa que sintetiza essa vontade comum de buscar meios adequados de preservação da vida digna mundial.

No entanto, o excesso de luminosidade ${ }^{16}$ é prejudicial tanto para a democracia quanto para a socialidade das relações humanas. Quem acredita que o alcance da transparência se circunscreva tão somente quanto à dimensão pública das atividades governamentais ou, ainda, na proteção de determinados bens juridicamente tuteláveis se equivoca (HAN, 2017, p. 50-53). Há um sério fator que, numa perspectiva social, pode deteriorar as teias de socialidade criadas pelo cotidiano das pessoas.

Segundo Han, o excesso de positividade ${ }^{17}$ que se observa em todas as sociedades é fator de sua autofagia. Não existe lugar para a negatividade na ideologia hipócrita do self made man. "Tudo é possível, basta ter boa vontade". "Tudo é possível, basta acreditar". "Tudo é possível, somente é pobre quem quer". Esses são os mantras da atualidade, garantidores de sucesso pessoal e profissional. Não existe lugar para alteridade ${ }^{18}$, para a negatividade, para a dialética entre os diferentes, para o mistério de viver e conviver.

O mais significativo exemplo de uma vida dedicada inteiramente às exigências do mercado para se participar ativamente deste jogo chamado democracia e de sua dimensão relacional entre as pessoas pode ser descrita na figura do trabalho. $\mathrm{O}$ ato de trabalhar é valor humano no qual traz sentido ao que se imagina, se cria e se produz. Toda relação de trabalho somente se justifica com a presença de uma outra pessoa. Ninguém trabalha

\footnotetext{
16 “[...] Uma total 'iluminação' iria carbonizar a alma e provocar nela uma espécie de burnout psíquico. Só a máquina é transparente; a espontaneidade - capacidade de fazer acontecer - e a liberdade, que perfazem como tal a vida, não admitem transparência" (HAN, 2017, p. 70-72).

17 “As instituições políticas e empresariais mudaram o sistema de punição, hierarquia e combate ao concorrente pelas positividades do estímulo, eficiência e reconhecimento social pela superação das próprias limitações” (HAN, 2017, p. 1102).

18 “[...] os rostos não se esgotam, mas transcendem pelas (infinitas) experiências compartilhadas. O Rosto quando reconhece Outro, provoca o transcender humano, gera a transformação na qual o sujeito, sozinho, não teria condições de realizá-la" (AQUINO, 2016, p. 200).
} 
exclusivamente para atender ao seu próprio interesse. A partir desse pensamento, trabalho pressupõe alteridade. As origens de uma sociedade capitalista dependem dessa condição. Aliás, como enfatiza Marx (2017, p. 690): “[...] Acumulação do capital é, portanto, multiplicação do proletariado".

Eis o impacto da epifania: A acumulação de capital depende da exploração do ser humano, o qual não tem os meios necessários para competir - em velocidade e quantidade - com as industrias. O ser humano explora outro ser humano e se criam mais e mais nichos de mercado para se atender aos - novos e crescentes - desejos da humanidade.

Na Sociedade da Transparência, contudo, o Outro é eliminado desse jogo. Basta que prevaleça a vontade individual e sua capacidade camaleônica de atender aos interesses que tragam sucesso, comodidade e estabilidade financeira. Como se realiza essa condição: pela hiperexposição da pessoa nas redes sociais virtuais. Transparência, nesse sentido, denota excesso de luminosidade, de desnudez da nossa humanidade, de desencobrimento daquilo que é a matriz de toda a condição relacional, qual seja, o segredo que, juntos, se descobre e se compartilha.

Não é possível afirmar que, agora, aquelas pessoas as quais exercem cargos hierarquicamente superiores - seja qual for o cenário - podem ser consideradas como os genuínos exploradores do trabalho alheio. Essa situação, que reconhece na alteridade sua matriz de significalidade, era clara no tempo do velho Marx. No momento presente deste século XXI, contudo, essa condição desapareceu. É a própria pessoa que explora, desmedidamente, a sua exposição nas redes sociais a fim de entoar o mantra da alta positividade. A liberdade da realização pessoal autoriza a exploração sem limites da força criativa humana. Quem nega o excesso dessa positividade, quem causa a alienação pessoal em detrimento ao mundo é o próprio ego.

O mistério do existir se torna raso, plano. Elimina-se qualquer forma de negatividade na qual gera a dúvida, a proximidade, a vontade de conhecer, de experimentar aquilo que extrapola as fronteiras do ego. As relações sociais se assemelham ao cálculo e previsibilidade das ações governamentais orientadas pela transparência. A (hiper)velocidade das relações humanas numa Sociedade da Transparência não pode 
incluir o tempo próprio de maturação acerca da descoberta sobre o Outro. Nesse caso, para Han (2017, p. 809), o sistema diminui, retarda essa velocidade de tudo conectar e expor. Essa condição, alimentada pelo capital mercantil transnacional, gera o inferno dos iguais, ou seja, uma igualdade transparente é uma igualdade opaca.

A transparência, entendida como pilar da dimensão relacional humana, não provoca nenhuma reflexão sobre o mistério que é o Outro e realiza o convite para se sair das certezas habituais criadas pelo ego. Nesse caso, ressalta Han (2017, p. 77/78): "[...] O ser humano sequer é transparente para consigo mesmo". Não existe humanização junto com o Outro, mas apenas um relacionar-se com o vazio. Por esse motivo, a socialidade movida pela transparência é pornográfica ${ }^{19}$, obscena, incapaz de fomentar a proximidade, o estarjunto-com-o-Outro-no-Mundo.

Toda relação humana precisa desse momento do mistério, daquilo que se esconde no oculto de cada ser humano, daquilo que povo as galerias subterrâneas das individualidades. É aqui que a epifania surge como o estrondoso trovão. Quando, contudo, o segredo ${ }^{20}$ é exposto, perde-se o encantamento da descoberta. A nudez transparente de todo ser fulmina a esperança do convite feito pela socialidade.

A Sociedade da Transparência se manifesta pela coação da exposição. Todos precisam se desfazer de suas totalidades existenciais e serem sinceros uns com os outros. A transparência é medida de violência que segrega ao invés de promover cenários para a inclusão. A imposição da transparência como o imperativo categórico de nosso tempo desconhece aquilo que se forma atrás de tantas mascaras que utilizamos e permitem a

\footnotetext{
19 “[...] O corpo pornográfico é raso, não é interrompido por nada. A interrupção cria uma ambivalência, uma ambiguidade. Essa imprecisão semântica é erótica. [...] É precisamente onde desaparece o mistério em prol da exposição e do desnudamento total que começa a pornografia. Ela é marcada por uma positividade penetrante, incisiva" (HAN, 2017, p. 518-522).

${ }^{20}$ Em sentido contrário, Bobbio sinaliza a importância da transparência contra o segredo na democracia. Num sentido institucional, de se consolidar a gestão da coisa pública diante da Sociedade, a transparência é uma exigência legal: "A democracia é idealmente o governo do poder visível, isto é, do governo cujos atos se desenrolam em público e sob o controle da opinião pública. [...] Como ideal de governo visível, a democracia sempre foi contraposta a qualquer forma de autoritarismo, a todas as formas de governo em que o sumo poder é exercitado de modo subtraído na maior medida possível dos olhos dos súditos" (BOBBIO, 2015, p. 29-30).
} 
flexibilidade das interações humanas todos os dias. Existem limites inclusive quanto à sinceridade transparente ${ }^{21}$.

A partir de todos esses fatos, não é possível existir qualquer manifestação de socialidade numa Sociedade da Transparência. Sem socialidade, a Sustentabilidade social é apenas uma ideologia criada e disseminada a fim de descrever todas as formas de conectividade entre as pessoas, sendo prejudiciais ou não. A função crítica da Sustentabilidade social se assemelha ao papel da Ética ${ }^{22}$ como vetor de promoção e desenvolvimento da nossa permanente humanização. A dimensão relacional humana não pode ser um nome vazio, não pode insistir nessa coerção imposta pelo imperativo da transparência. O jogo do existir é ambíguo, caleidoscópico, demanda paciência para que, no seu próprio tempo, crie sensações e significados capazes de alterar nosso modus vivendi uns com os outros, sejam humanos, sejam não humanos.

O "Direito de ser humano", dentro da lógica da Sustentabilidade social, jamais elimina a diferença, a negatividade e a alteridade, ao contrário, exige essas presenças como fundamento primeiro da convivência e aperfeiçoamento dos espaços democráticos. A Sociedade da Transparência exige luminosidade para compor as relações entre as pessoas semelhante àquela do século XVIII para afastar o obscurantismo da Idade Média. No entanto, hoje, essa obsessão pela exposição de tudo e todos causa efeitos altamente prejudiciais para o desenvolvimento sadio de nossa psyché. Não é possível viver, tampouco conviver, nas regras desse jogo.

Por esse motivo, a Sustentabilidade social se orienta por uma luminosidade mais sensível, diferente daquela que cega e desintegra a tessitura relacional humana. Diferente da luminosidade exigida pela transparência, a da Sustentabilidade social se assemelha a uma vela na qual permite ver o caminho sem retirar os mistérios que estão a cada passo do horizonte.

\footnotetext{
21 “A coação por exposição explora o visível. A seu modo, a superfície brilhante é transparente, não tendo necessidade de sofrer qualquer outro questionamento e não possuindo estrutura hermenêutica profunda" (HAN, 2017, p. 271273).

22 "[...] a intersubjetividade assimétrica é o lugar de uma transcendência na qual o sujeito, ao mesmo tempo em que conserva sua estrutura de sujeito, tem a possibilidade de não retornar fatalmente a si mesmo, de ser fecundo e antecipando, digamo-lo - de ter um filho" (LÉVINAS, 1998, p. 114).
} 
A exigibilidade da Dignidade Humana, por exemplo, somente tem legitimidade legal e social na medida em que compreende as virtudes e vícios do existir e conviver dentro daquilo que é oculto a cada homem e mulher. Esse é o convite. A decisão de aceitá-lo ou não depende de cada pessoa no seu próprio tempo. As consequências - positivas ou negativas - dessa tomada de decisão, sugerem o grau de compreensão entre a Sustentabilidade social e a Sociedade da Transparência para reivindicar o nosso "Direito de ser humano".

\section{PELO DIREITO DE SER HUMANO: SUSTENTABILIDADE SOCIAL NA SOCIEDADE DA}

\section{TRANSPARENCIA}

Viver e entender essa tragédia perpétua que é o existir humano nunca foi nossa maior especialidade. No início deste século XXI, ao invés de se identificar, disseminar, respeitar e constituir novos valores, bem como novos modos de convivência mais harmoniosos, prefere-se a xenofobia, o medo, a intolerância, a corrupção, os espaços mais autoritários em detrimento aos democráticos. Todo avanço civilizatório surge com perdas, com renúncias, pela indignação ${ }^{23}$ contra as atitudes que segregam, humilham, violentam a experiência de ser humano.

A busca pela perene humanização não é algo que se manifesta imediatamente aos olhos, à consciência, tampouco à experiência do sensível ${ }^{24}$. Ser humano, nesses tempos de ódio e desprezo pelo estranho, é fonte de resistência contra a animalidade que a todos habita. É descobrir nas galerias mais escuras, subterrâneas, de todas as relações empreendidas por cada pessoa no seu cotidiano aquilo que não faz sentido no monólogo -

\footnotetext{
23 “A indignação não é um ímpeto de raiva ou de desespero, nem um impulso oportunista ou egoísta, mas um reconhecimento natural de nossa condição humana. É o primeiro e necessário passo para nos alcançarmos por inteiro. A dignidade humana é o nosso produto maior, não somente como vida, mas como razão de viver. A dignidade não se confunde, tampouco, com uma ânsia de santidade ou uma conquista de honrarias: ela é, essencialmente, uma posição de respeito do homem para consigo mesmo em defesa da qualidade moral que representa" (LONGO, 2004, p. 175).

24 "Vivemos porque podemos ver, ouvir, sentir, saborear o mundo que nos circunda. E somente graças ao sensível chegamos a pensar: sem as imagens que nossos sentidos são capazes de captar, nossos conceitos, tal qual já se escreveu, não passariam de regras vazias, operações conduzidas sobre o nada. A influência da sensação e do sensível sobre nossa vida é enorme, embora permaneça praticamente inexplorada. Enfeitiçada pelas faculdades superiores, a filosofia raramente mediu o peso da sensibilidade sobre a existência humana. Esforçando-se por provar e fundar a racionalidade do homem, procurando separá-lo a qualquer custo do resto dos animais, ela frequentemente esqueceu que todo homem vive no meio da experiência sensível e que pode sobreviver apenas graças às sensações" (COCCIA, 2010, p. 9).
} 
e certezas habituais - do ego. Nesse momento, na beleza de um milésimo de segundo, as brumas que formam nossa cegueira - moral, científica, cultural - se desfazem.

O Direito, como expressão da resolução de nossos conflitos e instrumento que assegura aquilo no qual torna o viver e conviver mais digno e sadio, precisa respaldar essa atitude ética ${ }^{25}$ que se manifesta pela habitualidade do ir e vir das diferenças entre as pessoas. Insiste-se: Direito não é exclusivamente sinônimo de lei $^{26}$, porém a atividade legislativa, para fins de produzir a segurança jurídica, deve identificar essa correlação entre o comando normativo e o mundo da vida.

O "Direito de ser humano" se revela como a conquista permanente da Justiça e Dignidade Humana, ou seja, é a antítese da Sociedade da Transparência. Para se satisfazer a compreensão dessas duas categorias, destaca-se alguns elementos importantes que corroborem essa tarefa, tais como: a imbricação do Direito com o Homem e a Vida, a necessidade da autoconstrução humana, a revisão do Homem ético e justo, (re)descobrir o direito do cidadão, a utopia e o Direito, qual o papel das misérias humanas e da dignidade do Direito. Esse mosaico nos permite, minimamente, compreender qual é a finalidade do Direito dentro dos objetivos postos pela Sustentabilidade social.

O primeiro item se mostra como a contínua construção e fundação do Direito por meio das relações humanas. Muito embora os códigos e as leis não tenham o alcance ou o sentido profundo daquilo que se manifesta como atitude em prol de uma paz duradoura, de tolerância ${ }^{27}$ no cotidiano, a sua função técnica legitima, ainda, uma forma de

\footnotetext{
25 “[...] o que pode existir de mais valioso na vida, quer dos indivíduos, quer dos povos, senão alcançar a plena felicidade? Pois é disto exatamente que se trata quando falamos em ética. [...] a felicidade não é uma dádiva, e sim a recompensa de um esforço constante e bem orientado. Daí a importância suprema da investigação sobre o que é bom ou mau para se alcançar esse objetivo, [...]" (COMPARATO, 2006, p. 17).

26 “[...] O Direito não é só a lei, a norma de conduta na vida social. O Direito é mais que isso: é a humanização da Justiça. Antes mesmo de ser uma obra corporificada do homem, o Direito já existe como uma figura ideal, segura e necessária ao relacionamento humano. Tanto assim, que malgrado a incineração de todos os código ou a violação de todas as leis, o Direito subsistirá sempre como uma essência da vida social. É comum a todos, independentemente de nossas vontades, de nossas dependências, de nossos interesses ou gostos. [...] o Direito existe em si e por si, como uma substância aristotélica. É um ser, um substantivo, um núcleo, e não uma qualidade, um adjetivo, um adjunto" (LONGO, 2004, p. 26-27).

27 “A Tolerância torna visíveis os limites de nossas certezas e acolhe essa diferença que está além das fronteiras perceptivas do 'Eu'. Essa postura é inexistente por aquele que pratica o seu contrário - a intolerância -, porque a ausência desse terreno fértil, de se acolher a diferença humana alheia, impõe um modus vivendi sem liberdades, sem proximidade. É a negação da condição (e natureza) humana. Tolerar exige, sob esse argumento, o Perdão, pois, como salienta Voltaire, é o fundamento que se manifesta a partir do reconhecimento no qual se comunga nossas
} 
organização social. No entanto, quando se observa as convergências entre essas duas realidades, a legislação o espelho de nossa humanidade. No entanto, quando se subverte esse cenário, a imoralidade, o critério antiético aparece com as vestes de legalidade.

Nesse momento, existe uma categoria, um pressuposto necessário que impulsiona e dirige o sentido de se estabelecer esse diálogo contínuo sem a luminosidade excessiva da transparência cause nossa cegueira moral, qual seja: a vida. Esse é o alicerce fundamental dos costumes, das leis, enfim, torna-se o próprio sentido metamórfico do Direito no tempo e espaço. No momento que o Direito, no seu sentido normativo, se torna incapaz de assegurar as novas manifestações de respeito, de atitudes éticas, de responsabilidade, de cuidado dos seres humanos entre os seus semelhantes, sejam esses pertencentes à família antropos ou não, essa expressão que representa a paz se torna apenas um nome vazio.

Nesses tempos de Estado Pós-Democrático ${ }^{28}$, avalizado pelas "elites do atraso"29, defender os preceitos constitucionais, especialmente aos mais vulneráveis, se torna um ato de coragem, de fomente às utopias carregadas de esperança contra o ódio à democracia $^{30}$, o desespero, a sobrevivência. No entanto, a exigibilidade do direito a ser humano é, ainda, um convite para que não se possa apequenas a vontade popular, sobrepô-la aos interesses individuais. Precisa-se, nesse horizonte, caminhar com passos firmes em terrenos pantanosos. Eis o preço para se preservar a liberdade ${ }^{31}$ de todos.

fragilidades, nossos erros. Ao se admitir essa condição, intrassubjetiva e intersubjetiva, resta a indagação: Por que não perdoar? Percebe-se nessa ação uma aposta de regeneração, ao contrário da intolerância, que dissemina atitudes destrutivas. O improvável se corporifica e resiste, manifesta-se contra a violência, a crueldade, as imposições culturais arbitrárias e regenera as relações humanas tornando-as mais amistosas e sadias. Esse é o vínculo de Responsabilidade na qual se constitui historicamente por meio do 'estar junto', e se torna o sedimento que amplia o exercício habitual da Tolerância” (ZAMBAM; AQUINO, 2018, p. 374).

28 “Os sintomas pós-democráticos estão presentes na sociedade, da mercantilização do mundo à sociedade do espetáculo, do despotismo do mercado ao narcisismo extremo, da reaproximação entre o poder político e o poder econômico ao crescimento do pensamento autoritário, valores democráticos e dos correlatos limites rígidos ao exercício do poder, que hoje existem apenas como um simulacro, como um totem que evoca conquistas civilizatórias do passado, mas que hoje não passam de lembranças que confortam" (CASARA, 2017, p. 181-184).

${ }^{29}$ Todo racismo, inclusive o culturalismo racista dominante no mundo inteiro, precisa escravizar o oprimido no seu espírito e não apenas no seu corpo. Colonizar o espírito e as ideias de alguém é o primeiro passo para controlar seu corpo e seu bolso" (SOUZA, 2017, p. 312-313).

${ }^{30}$ É necessário insistir: "[...] a democracia não é nem uma sociedade a governar nem um governo da sociedade, mas é propriamente esse ingovernável sobre o qual todo o governo deve, em última análise, descobrir-se fundamentado" (RANCIÈRE, 2014, p. 66).

31 “Para usar uma distinção medieval, não somos apenas 'pacientes' cujas necessidades merecem consideração, mas também 'agentes' cuja liberdade de decidir o que valorizar e a forma de buscá-la pode se estender muito além de nossos próprios interesses e necessidades. O significado de nossa vida não pode ser colocado num caixinha de nossos 
Devido a essas intempéries, a autoconstrução humana se torna indispensável na medida em que se pode visualizar a importância do papel desempenhado pelo conhecimento humano, o seu alcance e limites. A vida mostra-se pelas suas múltiplas dimensões. Nesse caleidoscópio, a construção de uma unidade do conhecimento funda-se como um árduo desígnio. Entretanto, o querer compartimentalizar o conhecimento para melhor apreendê-lo (História, Filosofia, Antropologia, Sociologia, Medicina, Biologia, entre outros) não significa apenas analisar a superfície de seus conceitos, como se enxergássemos tão somente o horizonte do mar. É necessário mergulhar na sua profundidade a fim de conhecer seu alcance, sua estrutura, a sua identificação.

O pensamento não remonta apenas o diálogo racional, mas entre esse e todos os elementos que perfazem a cognição ${ }^{32}$ humana, especialmente os de natureza emocional e afetiva. Efetivar o Direito não reside num sentido puramente doutrinário ou jurisprudencial, porém encontra-se, também, nas tessituras relacionais que permitem sentir a vida e suas dificuldades. Nesse sentido, o homem justo e ético deve se fazer presente, pois quando questiona as ações imorais e amorais de seu tempo, quando se indigna contra a corrupção, a atuação desmedida de uma globalização mercantil na qual acentua as profundas desigualdades globais. Essa é a força anímica para fundar o Direito contra as mazelas humanas. Por meio do ser ético, a norma jurídica promove a Dignidade Humana ao afirmar a liberdade como condição de sua legitimidade. Cita-se como exemplo dessa afirmação a Declaração dos Direitos Humanos.

O sentido do Homem ético e justo denota ser Cidadão. O conceito de Cidadania ${ }^{33}$ não se exaure mais pela relação entre o Estado e Sociedade. O surgimento de diferentes

padrões de vida ou da satisfação de nossas necessidades. As necessidades manifestas do paciente, por mais importantes que sejam, não podem eclipsar a relevância vital dos valores arrazoados do agente" (SEN, 2011, p. 286).

32 "A ideia central da teoria de Santiago é a identificação da cognição, o processo de conhecimento, com o processo do viver. [...] cognição é a atividade que garante a autogeração e a autoperpetuação das redes vivas. Em outras palavras, é o próprio processo da vida. A atividade organizadora dos sistemas vivos, em todos os níveis de vida, é uma atividade mental. As interações de um organismo vivo - vegetal, animal ou humano - com seu ambiente são interações cognitivas. Assim, a vida e a cognição tornam-se inseparavelmente ligadas. A mente - ou melhor, a atividade mental - é algo imanente à matéria, em todos os níveis de vida" (CAPRA, 2005, p. 50).

33 “[...] A cidadania não poderia então nesse momento ser definida a partir apenas dos textos jurídicos que fixam alguns de seus atributos: ela evoca uma realidade mais difusa e mais profunda, atingindo as próprias raízes da identidade individual e coletiva; a cidadania apresenta-se como um estatuto, mais ou menos interiorizado por cada qual ao termo de um processo de aprendizado, que fixa as modalidades e as formas de pertinência ao grupo de referência" (CHEVALLIER, 2009, p. 252). 
atores que constituem outros cenários e espaços para a articulação de políticas quanto ao uso de bens comuns supera os interesses nacionais. Cidadania, como medida de reconhecimento de nosso vinculo comum de humanidade, é a condição política e jurídica que torna possível identificar a Terra como nossa pátria. Exemplos para esse fenômeno não faltam, pois tem Cidadania Europeia, Cidadania Sul-Americana ${ }^{34}$, pode-se cogitar numa Cidadania Mundial a partir da Declaração de Direitos Humanos. Essa proximidade entre tantas culturas diferentes esclarece o que significa ser humano e ter direito a ser humano para se desenvolver uma civilização fundada no valor da cadeia vital terrestre.

A partir dessa condição, os limites de sua soberania são expostos e demandam uma tessitura comum por meio de compartilhamento daquilo que é comum e indispensável à vida e dignidade. Essa relação mais ampla, de conjugação dos esforços para mitigar as profundas desigualdades faz transparecer uma relação entre Cidadãos, Sociedades e Estados enraizadas em princípios éticos jurídicos. Nesse caso, a práxis cidadã se torna uma virtude, reforçada pelos Tratados Internacionais (bilaterais, plurilaterais, multilaterais) e pelas Constituições nacionais.

Por todos esses motivos, insiste-se: o direito de ser humano é uma utopia perpétua. Ao contrário do que o vocábulo significa nos meios populares, representa-se a viva força construtora de nossa humanidade compartilhada no decorrer do tempo. Essa força advém de uma sensibilidade ética e social em querer edificar um novo sentido para viver, não somente para o presente, mas igualmente, para o futuro. As novas conquistas que surgem desses esclarecimentos não admitem retrocesso no trato do humano em sua humanidade.

A privação de ser humano, motivadas pela alta exposição de presenças objetificadas na rede virtual mundial, de mercadorias que estão à venda nos jogos das

\footnotetext{
34 “Representa a erosão do conceito político de Cidadania estabelecido pelo Estado-nação e torna cada indivíduo capaz de agir como protagonista dessa condição civilizatória transfronteiriça. Essa categoria, de natureza multilateral, surge como projeto histórico de transformação e integração humana, perene, inscrita pela sua diversidade cultural. A referida diversidade constitui a sua unidade continental compreendida pela expressão: "um em todos, todos em um". A sua existência demanda uma instância continental capaz de criar direitos os quais assegurem regras ao seu exercício e exigibilidade. A sua previsão legal - seja nos tratados constitutivos ou numa possível Carta de Princípios e Garantias Fundamentais - não representa preocupação etnocêntrica de se identificar os iguais, conforme se observa na constituição da comunidade nacional, mas para estabelecer cenários de Fraternidade, com maior número de participantes responsáveis pela proteção de um patrimônio comum descrito pelo diálogo indivíduo-sociedade-espécie e a Terra" (AQUINO, 2014, p. 19).
} 
interações - mercantis - humanas, do excesso de positividade, de good vibes permanentes, geram a angústia, a frustração de não ser igual, de, tampouco, usufruir da Liberdade de se estar em todos os lugares desejáveis. A Liberdade e Igualdade de uma Sociedade da Transparência pouco contribui à efetividade do "Direito de ser humano".

Rememorar, de modo permanente, as conquistas de preservação de nossa humanidade e fomentar os novos parâmetros para se ter, sempre mais, dignidade ratifica a função social e utópica da norma jurídica contra as misérias humanas. A miséria, por ser um estado de irracionalidade, está abaixo do mínimo de condições de humanidade e não pode ser confundido com a pobreza. Essa é o poço sem fundo e aquela o fundo do poço ${ }^{35}$.

A Constituição Federal, por exemplo, combate a pobreza, mas não conceitua ou identifica o que é miséria. Outros termos designados para serem semelhantes à miséria como setores desfavorecidos ou marginalização não podem ter essa denotação, pois são conceitos muito genéricos, sem qualquer precisão da carga semântica ou de seus limites. Nesse sentido, quando não se consegue afirmar o que é a riqueza humana, não se consegue visualizar a miséria. Os remédios jurídicos não conseguem intervir ou suprir as suas carências.

A função de um Profissional do Direito comprometido em identificar a novidade do novo (ZIZEK, 2011, p. 145) - especialmente no que se refere às violências contra a liberdade, a supressão da igualdade, o esmaecimento da fraternidade, justiça e solidariedade - reforça o seu agir em prol do desvelo de nossa humanidade que habita o Outro, seja humano ou não.

Qual seria, diante desses argumentos, o fim do Direito ${ }^{36}$ ? Ou, dito forma diferente, qual é a finalidade do "Direito a ser humano" na Sociedade da Transparência? É a busca pela viabilidade, pela luta, pela identificação, pela exigibilidade e pela preservação de uma

\footnotetext{
35 “[...] Nem todos necessariamente pobres ou miseráveis, nem contingencialmente ricos e poderosos, mas todos, de forma voluntária ou involuntária, estamos irremediavelmente condenados ao destino miserável e infernal da desumanidade" (LONGO, 2004, p. 145).

36 “O Direito herdado da Modernidade é um direito rígido, que exclui de sua dimensão a subjetividade humana. Marcado pelo rigorismo científico, torna-se mouco às súplicas de justiça. Com o advento da Pós-Modernidade, enquanto espaço de produção do novo, e por isso, vetor de modificação, incute consequências - não apenas, mas também - ao Direito. É preciso refletir, (re)pensar e (re)examinar esse fenômeno sociocultural, recompondo-o com as novas perspectivas, a partir daquilo que enuncia o espírito de outro tempo, outras necessidades, outros valores". (DAL MAGRO; AQUINO, 2017, p. 122).
} 
vida digna e uma convivência harmoniosa. É o poder se indignar sem apelar aos exageros dos sentimentos e os da racionalidade - especialmente instrumental -, da vingança privada, da destruição comum alimentada pelas ideologias fanáticas. É a busca pela unidade de nossa humanidade compartilhada escondida em tantas galerias subterrâneas de nosso cotidiano no mundo. O Outro é um segredo perpétuo que, quando desvelado, mostra a realidade humana de nossos egos. Eis os desafios postos pelo significado sincrônico e diacrônico da Sustentabilidade social.

A percepção desse multiverso de pensamentos e ações tem como consequência a produção, interpretação e aplicação de novos direitos, fruto desta alargada compreensão sobre o que significa ser humano em correlação aos seus semelhantes e ao mundo. Tem como exemplo: Direito à Sustentabilidade, Direitos da Natureza, a Legislação ambiental, a Lei Maria da Penha, Jurisdição Indígena Originária Campesina, a Arbitragem como forma de acesso à justiça, especialmente nas demandas transnacionais, Biodireito e Bioética, enfim, todos esses fenômenos prescrevem alguns desses elementos necessários para a concretização da Justiça, não obstante, como já dito, muitos estão, ainda, sob a superfície do oceano.

Entretanto, o sentido ético e do cuidado que se manifesta nessas normas jurídicas não sintetizam a integralidade de ser humano, pois a generalidade de seus preceitos pouco ou nada abarca sobre as raízes mais fundas nas quais edificam o existir humano. Por esse motivo, quando a Sociedade da Transparência elimina, pela intensidade de suas luzes, os mistérios que nos convidam a sair de nossas individualidades mais egoístas e abraçar o desconhecido, a nossa humanização se perde nos delírios econômicos e na salvação do progresso científico e tecnológico. Ser humano: eis o nosso maior enigma em todos os tempos históricos.

\section{CONCLUSÃO}

Desde o século XVIII, o tempo das luzes da racionalidade, há algo superestimado entre os seres humanos: o esclarecimento do mundo e de si dado pelo cogito. Apoiar-se nessa premissa não soa como a melhor as respostas para um mundo complexo. É necessário averiguar como essa "luz" incide em nossa percepção - "Eu", "Tu", "Nós", 
"Mundo". A partir desse momento, sabe-se que o excesso de "luz" pode cegar e prejudicar qualquer compreensão que exija o reconhecimento acerca da alteridade nos sujeitos anteriormente mencionados.

Esse parece ser a linha condutora sobre Sustentabilidade social e Sociedade da Transparência. A demanda por essa expressão, principalmente no seu significado institucional, serve para fortalecer a democracia e a condução daquilo que pertence ao espaço público. Mesmo Bobbio já havia sinalizado a sua necessidade para se evitar segredos que podem surgir na relação Estado e Sociedade. Não obstante, o mesmo autor insistiu, também, nos limites da transparência a fim de se evitar o temor e a desorganização social.

A Sociedade da Transparência se caracteriza dentro dessa linha de pensamento. A exigência da transparência nas relações sociais não a enaltece como verdadeira, mas causa o seu esgotamento. A dimensão relacional humana não se movimenta pelas luzes do que as pessoas são, mas pelo convite daquilo que não se mostra, daquilo que é um mistério ao limites de nosso intelecto e sensibilidade.

O que se constata pela Sociedade da Transparência é que todos se transformaram em mercadorias. Todos estão expostos no grande mercado mundial virtual. Essa hiperexposição, entendida como a regra do jogo da socialidade contemporânea, dilacera o imaginário constituído pelo convite daquilo que é oculto na dimensão relacional. A quantidade exagerada de luz causada pela transparência total, ao se resgatar a metáfora proposta no início destas conclusões, elimina toda chance de constituição das relações humanas. Somos indivíduos que exaltam suas qualidades pessoais nesse grande mercado. Não queremos conviver, queremos ser comprados pelo maior preço.

Por esse motivo, e contra a falsa socialidade criada pela Sociedade da Transparência, é necessário um imperativo ético, capaz de permitir uma atitude crítica na qual mitigue os efeitos luminosos e econômicos deste intenso não-estar-junto-com-oOutro-no-Mundo. A Sustentabilidade, na sua dimensão social, compreende a necessidade de algum equilíbrio entre o que acontece nas macro e microestruturas sociais. A sobreposição de uma na outra faz desaparecer sua característica homeostática porque, fatalmente, faz desparecer o "Outro" diante do "Eu". 
Sem que haja, minimamente, essa simbiose, como se pode reivindicar condições capazes de nos humanizar no decorrer do tempo e que se tornam indispensáveis a esse projeto chamado Sociedade, seja a local ou a mundial? Nessa linha de pensamento, somente se torna possível exigir um Direito de ser humano na medida em que se tem elementos cujos propósitos são para evitar a nossa cegueira diante de tantas luzes sobre nosso sentir, pensar e agir. A Sustentabilidade social traz indícios dessa preocupação no decorrer do tempo.

A partir dessas afirmações, pode-se concluir que a hipótese de pesquisa descrita na Introdução deste estudo foi confirmada, pois a Sociedade da Transparência, ao prescrever alguns modos de integração prejudiciais às relações intersubjetivas, impedem que o mistério entre o "Eu" e o "Tu" favoreça o encontro entre diferentes percepções e intensifique a nossa humanização. Nesse caso, a Sustentabilidade social indica quais metamorfoses viabilizam a amplitude e reivindicação do "Direito de ser humano".

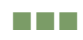

\section{REFERÊNCIAS}

AQUINO, Sérgio Ricardo Fernandes de. Por uma cidadania sul-americana: fundamentos de sua viabilidade pela UNASUL a partir da ética, fraternidade sustentabilidade e política jurídica. Saarsbrucken: Novas Edições Acadêmicas, 2014.

AQUINO, Sergio Ricardo Fernandes de. Raízes do direito na pós-modernidade. Itajaí, SC: Editora da UNIVALI, 2016.

BOBBIO, Norberto. Democracia e segredo. Tradução de Marco Aurélio Nogueira. São Paulo: UNESP, 2015.

CAPRA, Fritjof. As conexões ocultas: ciência para uma vida sustentável. Tradução de Marcelo Brandão Cipolla. São Paulo: Cultrix, 2005.

CASARA, Rubens. R. R. Estado pós-democrático: neoobscurantismo e gestão dos indesejáveis. [Versão Kindle]. Rio de Janeiro: Civilização Brasileira, 2017.

CHEVALLIER, Jacques. O Estado pós-moderno. Tradução de Marçal Justen Filho. Belo Horizonte: Fórum, 2009.

COCCIA, Emanuele. A vida sensível. Tradução de Diego Cervelin. Florianópolis: Cultura e Barbárie, 2010.

COMPARATO, Fábio Konder. Ética: direito, moral e religião no mundo moderno. São Paulo: Companhia das Letras, 2006. 
CORTINA, Adela. Cidadãos do mundo: para uma teoria da cidadania. Tradução de Silvana Cobucci Leite. São Paulo: Loyola, 2005.

DAL MAGRO, Diogo; AQUINO, Sergio Ricardo Fernandes de. O télos do direito na pósmodernidade: razão sensível, fraternidade e reconhecimento. In: AQUINO, Sergio Ricardo Fernandes de (org.). Palimpsesto: o direito. Erechim, RS: Deviant, 2017.

DURKHEIM, Émile. Da divisão do trabalho social. Tradução de Eduardo Brandão. 2. ed. São Paulo: Martins Fontes, 1999.

HAN, Byung-Chul. Sociedade da transparência. [Edição Kindle]. Tradução de Enio Paulo Giachini. Petrópolis, RJ: Vozes, 2017.

HUSSERL, Edmund. Conferencias de Paris. Tradução de António Fidalgo e Artur Morão. Lisboa: Edições 70, 1992.

IANNI, Octavio. A sociedade global. 13. ed. Rio de Janeiro: Civilização Brasileira, 2008.

LÉVINAS, Emmanuel. Da existência ao existente. Tradução de Paul Albert Simon. Campinas, SP: Papirus, 1998.

LONGO, Adão. O direito de ser humano. Rio de Janeiro: Forense Universitária, 2004.

MARX, Karl. O capital: o processo de produção do capital. [Livro 1]. Tradução de Rubens Enderle. São Paulo: Boitempo, 2017.

MORA, José Ferrarter. Dicionário de Filosofia. Tradução de Roberto Leal Ferreira e Álvaro Cabral. 4. ed. São Paulo: Martins Fontes, 2001.

MORIN, Edgar. A cabeça bem-feita: repensar a reformar, reformar o pensamento. Tradução de Eloá Jacobina. 10. ed. Rio de Janeiro: Bertrand Brasil, 2004.

MORIN, Edgar. O paradigma perdido: a natureza humana. Tradução de Hermano Neves. 6. ed. Mem Martins. Lisboa: Europa-América, 2000.

PASOLD, Cesar Luiz. Metodologia da pesquisa jurídica: teoria e prática. 14. ed. rev., amp. e atual. Florianópolis: Empório Modara, 2018.

RANCIÈRE, Jacques. O ódio à democracia. Tradução de Mariana Echalar. São Paulo: Boitempo, 2014.

SEN, Amartya. A ideia de justiça. Tradução de Denise Bottmann e Ricardo Doninelli Mendes. São Paulo: Companhia das Letras, 2011.

SOUZA, Jessé. A elite do atraso: Da escravidão à Lava Jato [Edição Kindle]. São Paulo: Leya, 2017.

STAFFEN, Márcio. Interfaces do direito global. 2. ed. Rio de Janeiro. Lúmen Juris, 2018.

ZAMBAM, Neuro José; AQUINO, Sérgio Ricardo Fernandes de. Tolerância: reflexões filosóficas, políticas e jurídicas para o século XXI. Revista da AJURIS. Porto Alegre, v. 142, n. 137, p. 374, março de 2015. Disponível em: <http://www.ajuris.org.br/OJS2/index.php/REVAJURIS/article/view/389/323>. Acesso em: 9 jan. 2018. 
ZIZEK, Slavoj. Primeiro como tragédia, depois como farsa. Tradução de Maria Beatriz de Medina. São Paulo: Boitempo, 2011.

AQUINO, Sérgio Ricardo Fernandes de. Sustentabilidade social, sociedade da transparência e o direito de ser humano. RBSD - Revista Brasileira de Sociologia do Direito, v. 6, n. 1, p. 151-174, jan./abr. 2019.

Recebido em: 08/07/2018

Aprovado em: 18/11/2018 